\title{
CADAVERINE AND PUTRESCINE LEVELS IN HUMAN BRAIN TISSUE FOR POSTMORTEM INTERVAL ESTIMATION
}

\author{
Abdelmonem G. Madboly ${ }^{* 1}$; Asmaa Y. A. Hussein*1; Eslam S. Metwally ${ }^{* 1}$ \\ ${ }^{1}$ Department of Forensic Medicine \& Clinical Toxicology, Faculty of Medicine, Benha \\ University, Egypt \\ Corresponding Author: Abdelmonem G. Madboly \\ Postal address: Faculty of Medicine, Benha University. Farid Nada Street, Benha City, Egypt. \\ Mobile No.: +201118734643 \\ Email: abdelmonem.algohari@ fmed.bu.edu.eg \\ Date of submission: 28 November 2020 \\ Revised at: 20 January 2021
}

Accepted at: 24 January 2021

ABSTRACT

Background: Estimation of the postmortem interval (PMI) is a pivotal task in forensic investigations. Methods that relied on PM biochemical alteration of the compounds such as cadaverine $(\mathrm{Cad})$, and putrescine (Put) can provide more accurate data about the exact PMI. Aim: To investigate the correlation between Cad and Put levels in human brain tissue, measured by gas chromatography-mass spectrometry (GC-MS) and the PMI, to see if they can be used as reliable indicators for PMI estimation. Methodology: Brain specimens were taken during the autopsy of three male victims who died from stab wounds. The autopsy was done within three hours after death (the moment of death was known). The fifteen brain specimens (five from each victim's brain, according to a fixed schedule to simulate progressive postmortem intervals) were prepared for injection into the GC-MS, and the levels of Cad and Put in the brain tissue specimens were measured. Results: Both Cad and Put levels increased in the brain tissue samples if the PMI increased. There was a statistically highly significant $(\mathrm{p}<0.0001)$ linear correlation between both Cad and Put levels and the PMI. The present study designed equations for estimating the PMI based on the determined $\mathrm{Cad}$ and Put levels in brain tissues [Cad level $=(0.03+8.33 \mathrm{E}-3 *$ timing $)$; Put level $=(0.09+$ $0.03 *$ timing)]. Conclusion: Both $\mathrm{Cad}$ and Put are considered valuable biomarkers for estimating the PMI, however, put as a biomarker of PMI is more accurate than Cad, as $99.5 \%$ of the variability of Put levels was due to the progressive timing of sampling, compared to that of Cad, which was only $75.2 \%$. MS.

KEYWORDS: Cadaverine, Putrescine, Human, Brain Tissue, Postmortem Interval, GC-

\section{INTRODUCTION}

Estimation of the postmortem interval (PMI) or the time passed since death is a pivotal task in forensic investigations (Shaaban et al., 2017; Kaliszan and Wujtewicz, 2019), but it is one of the most difficult determinations to make (Marhoff-Beard et al., 2018). A precise PMI can help in perpetrators identification, reduce the number of suspects, and verify witnesses' declarations (Nolan et al., 2019a).

Several methods used to determine the PMI have significant degrees of subjectivity, uncertainty, and contradiction, as decomposition is a complicated biological and chemical procedure, and because of many personal and environmental factors (Andersson et al., 2019; Connor et al., 2019). Methods relied on PM biochemical alteration of the compounds present in biological tissues and fluids can provide more accurate data about the exact PMI (Musile et al., 2019).

Biogenic amines (BA), like cadaverine $(\mathrm{Cad})$ and putrescine (Put) are naturally occurring nitrogenous compounds formed by the decarboxylation of amino acids. At the physiological level, BA have fundamental 
biological functions in humans (Navarro et al., 2020). Cadaverine (1,5diaminopentane) and putrescine (1,4butanediamine) are foul-smelling compounds, released as the proteincontaining tissues start decaying either in living or dead organisms (Ying et al., 2018).

Analytical methods have been used to analyze amino acids decomposition byproducts, as Cad and Put including high performance liquid chromatography, capillary zone electrophoresis, and gas chromatography-tandem mass spectrometry (Qi et al., 2018; Wu et al., 2018).

The investigation on Cad and Put as chemical biomarkers for PMI determination in human tissues has received little interest. Only a few studies on the detection of Cad and Put by GCMS technique had been published, despite of their great importance in forensic medicine, especially their usefulness in PMI estimation (Hess et al., 2018).

\section{AIM OF THE WORK}

This work was performed to investigate the correlation between cadaverine (Cad) and putrescine (Put) levels in human brain tissue, measured by the GC-MS, and the postmortem interval (PMI), to see if they can be used as reliable indicators for PMI estimation.

\section{SUBJECTS \& METHODS}

\section{Chemicals and reagents:}

Following chemicals and reagents were used:

- Standards (purity $\geq 99 \%$ ): cadaverine dihydrochloride, putrescine dihydrochloride \& N, O-Bis (trimethylsilyl) trifluoroacetamide (BSTFA) from Sigma Aldrich (3050 Spruce St., Saint Louis, USA).

- Solvents: distilled water, ethyl acetate, diethyl ether, sodium hydroxide, and methanol from El-Gomhouria Pharmaceutical Co. (23 Sawwah S., Amereya, Cairo, Egypt).

Specimen collection:
Inclusion criteria: fresh bodies, i.e., with a known postmortem interval $\leq 12 \mathrm{~h}$, died by injuries away from head and brain injuries. Exclusion criteria: cases known to suffer from any malignancy or preexisting cerebral diseases (detected during the autopsy), victims sustained brain injuries due to head trauma, and any cadaver with a postmortem interval $>12 \mathrm{~h}$.

Brain specimens were taken during the autopsy of three male victims, aged (40 y; $48 \mathrm{y}$ and $52 \mathrm{y}$ ), who died by stab wound injuries in the chest (case $1 \& 2$ ) and abdomen (case 3). Autopsy of the three cadavers was done within three hours after death. The three victims were transmitted alive to Benha Educational Hospital and died after a short period by severe hemorrhage \&/or injuries of vital internal organs (the moment of death was known for the three studied cadavers).

The autopsy was done by forensic physicians working at Qalubia Forensic Medicine Department, Forensic Medicine Authority, Ministry of Justice. The researchers collected the brain specimens: about $5 \mathrm{gm}$ specimen was excised from the parietal cortex of each of the three studied brains.

\section{Specimen preparation:}

The brain specimens were prepared according to Pelletti et al. (2019) as follows: each brain specimen was enclosed in a double layer of nylon to prevent evaporation of chemicals. Every specimen was put in a plastic container covered by an aluminum foil sheet to protect it from light.

Brain specimens were stored at room temperature (adjusted at 25॰ C) for a further $60 \mathrm{~h}$. to stimulate progressive putrefaction. Five aliquots $(50 \mathrm{mg}$ for each, weighed by ADP 210 Balance) were taken from each brain specimen according to a fixed schedule, to simulate progressive postmortem intervals, as follows:

- $\quad$ PMI1: $12 \mathrm{~h}$ after death.

- $\quad$ PMI2: $24 \mathrm{~h}$ after death.

- $\quad$ PMI3: $36 \mathrm{~h}$ after death.

- $\quad$ PMI4: $48 \mathrm{~h}$ after death. 
- $\quad$ PMI5: $60 \mathrm{~h}$ after death.

The fifteen brain aliquots were stored at $-25^{\circ} \mathrm{C}$. Each $50 \mathrm{mg}$ brain aliquot was homogenized twice (using IKA T-25 Ultra-Turrax Homogenizer, Germany) with a $10 \%$ solution of $\mathrm{NaOH}$. One $\mathrm{mL}$ of diethyl ether was used to purify the homogenates. The homogenates were centrifuged $(3000 \mathrm{rpm})$ for $10 \mathrm{~min}$, using (Eppendorf 5702R centrifuge, Germany) and the supernatants were separated.

The samples' $\mathrm{pH}$ was adjusted to be from (10-11) by addition of $40 \% \mathrm{NaOH}$. Extraction of samples was done twice by vortexing with $5 \mathrm{~mL}$ of diethyl ether using (Fisher Scientific Pulsing Vortex Mixer, USA). $100 \mathrm{ml}$ of formic acid methanolic solution $(5 \%)$ was added to both organic extracts. Then evaporation to dryness at $40^{\circ} \mathrm{C}$ under nitrogen evaporator was done. Derivatization of the extracted samples was done using $50 \mathrm{~mL}$ of (BSTFA) at $85^{\circ} \mathrm{C}$ for $45 \mathrm{~min}$. Reevaporation and reconstitution of the samples were done in ethyl acetate (120 $\mathrm{mL}$ ). The samples were injected into the Gas chromatography- Mass spectrophotometry.

\section{Calibrators:}

Linear calibration model within the range of $0.01-5 \mathrm{mg} / \mathrm{g}$. Powder standards of Cad \& Put were dissolved in methanol and used as calibrators at concentrations of $0.01,0.05,0.25,0.5,1,2.5$ and $5 \mathrm{mg} / \mathrm{g}$.

\section{GC/MS conditions:}

A TSQ Quantum triple quadrupole GC-MS/MS instrument coupled with a Thermo Scientific ${ }^{\text {TM }}$ TRACETM 1300 GC (Thermo Scientific, Austin, TX, USA) was used. Sample introduction was performed a Thermo Scientific ${ }^{\mathrm{TM}}$ AS3000 auto sampler and chromatographic separation using a Thermo Scientific ${ }^{\mathrm{TM}}$ Trace GOLD TG-5MS $30 \mathrm{~m} \times 0.25 \mathrm{~mm}$ I.D. $\times 0.25 \mu \mathrm{m}$ film capillary column.

Initial oven temperature of $50^{\circ} \mathrm{C}$ for 1 minute, increased by $10^{\circ} \mathrm{C} /$ minute up to $200^{\circ} \mathrm{C}$ and held for 30 seconds, ion source and interface was 250, and $270 \mathrm{C}$, respectively. The used carrier gas was helium at a flow rate of $0.7 \mathrm{~mL} /$ minute. The spitless injection was used. The mass spectrometer was adjusted in electron impact ionization/selective ion monitoring (EI/SIM) mode $(70 \mathrm{eV})$. The identification mass fragments used in this method were: $\mathrm{m} / \mathrm{z} 88,70,59,43$, and 30 for PUT and $\mathrm{m} / \mathrm{z} 102,85,56$, and 30 for CAD.

Quantitative analysis was done via external standardization method using a calibration curve made using serially diluted solutions containing known specified amounts of $\mathrm{Cad}$, and Put as standards; 0.01, 0.05, 0.25, 0.5, 1, 2.5 and $5 \mathrm{mg} / \mathrm{g}$, as described by Pelletti et al. (2019).

This study's protocol was approved by the Research Ethics Committee of Faculty of Medicine, Benha University [No. RC.6.9.2020]. A consent was taken from Qalubia Forensic Medicine Department, Forensic Medicine Authority, Ministry of Justice to take the human brain samples. All results obtained were registered in special sheets, which were confidential.

\section{Statistical analysis:}

The collected data were tabulated and analyzed using SPSS 21 microstate software package. For every set of data (Cad or Put levels), mean and standard deviation were measured. Multiple sample comparison was made by the analysis of variances (ANOVA), and an F-test was applied. The correlation coefficient was calculated. A p $<0.05$ was taken to indicate statistical significance (Khothari, 2004).

\section{RESULTS}

Both cadaverine (Cad) and putrescine (Put) were identified by comparison of their retention times and mass spectra with those of NIST 014 mass spectral database (Fig. 1\& 2).

\section{Selectivity}

All standard and tested samples were free of co-eluting peaks at the Cad \& Put analytes' retention times. The full scan mass spectrum of $\mathrm{Cad}$ and Put were shown in Fig. 1 \& 2. The method was thus 
considered adequate as no other analytes

were observed in the STD solution.
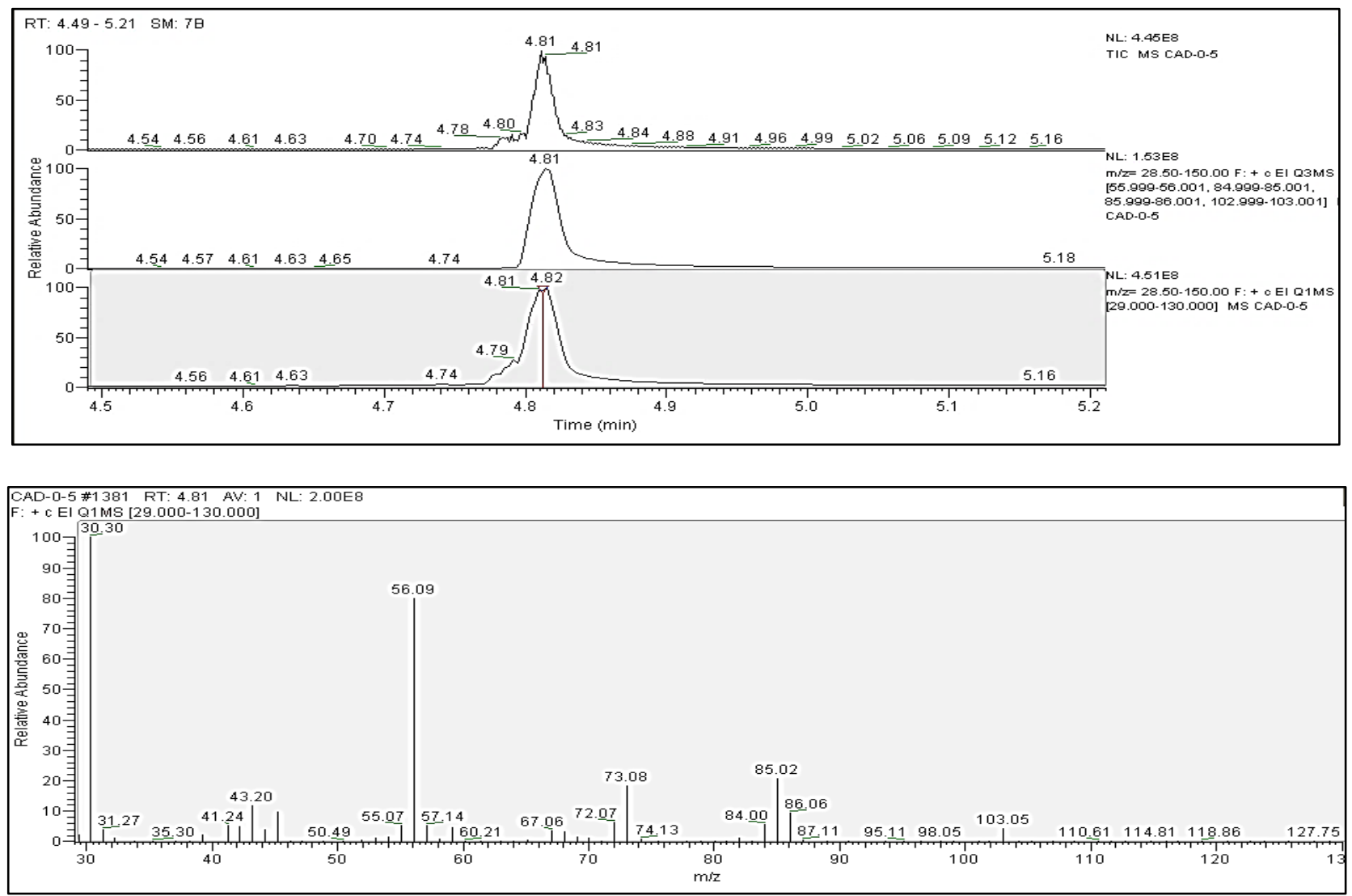

Figure (1): The chromatogram and full mass spectrum of cadaverine standard and mass fragments used in this SIM quantitation method. 

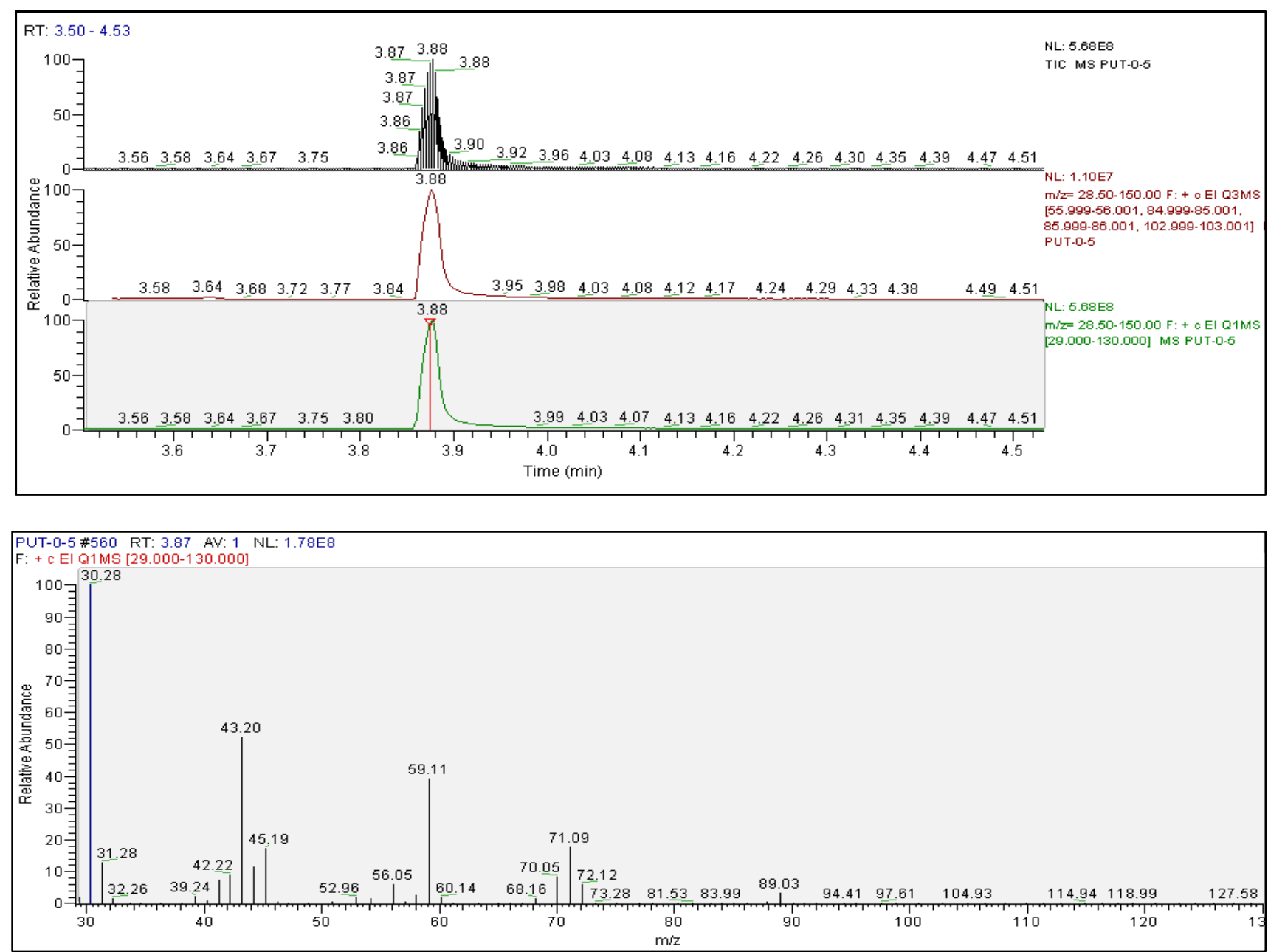

Figure (2): The chromatogram and full mass spectrum of putrescine standard and mass fragments used in this SIM quantitation method.

\section{Linearity}

All analytes were linear in range. The weighting factor was chosen as linear regression model for calibration curves. Correlation coefficients $\left(\mathrm{R}^{2}\right)$ were exceeding 0.9982 Cad \& 0.9993 Put. Linear regression equations were $\mathrm{Y}=$ $3.76377 \mathrm{e}+007+5.05777 \mathrm{e}+008 * \mathrm{X}, \quad$ where $\mathrm{R}^{\wedge 2}=0.9982$ for $\mathrm{Cad}$, and $\mathrm{Y}=$ $1.57855 \mathrm{e}+007+3.5251 \mathrm{e}+007 * \mathrm{X}, \quad$ where $\mathrm{R}^{\wedge 2}=0.9993$ for Put (Table 1 and Fig. 3 \& 4).

Table (1): Linearity, limit of detection (LOD), lower limit of quantification (LLOQ) for cadaverine and putrescine:

\begin{tabular}{|l|l|l|l|}
\hline Compound & Linearity $\left(\mathbf{R}^{\mathbf{2}}\right)$ & LOD $(\mathbf{m g} / \mathbf{g})$ & LLOQ $(\mathbf{m g} / \mathbf{g})$ \\
\hline Cadaverine & 0.9982 & 0.01 & 0.01 \\
\hline Putrescine & 0.9993 & 0.01 & 0.05 \\
\hline
\end{tabular}




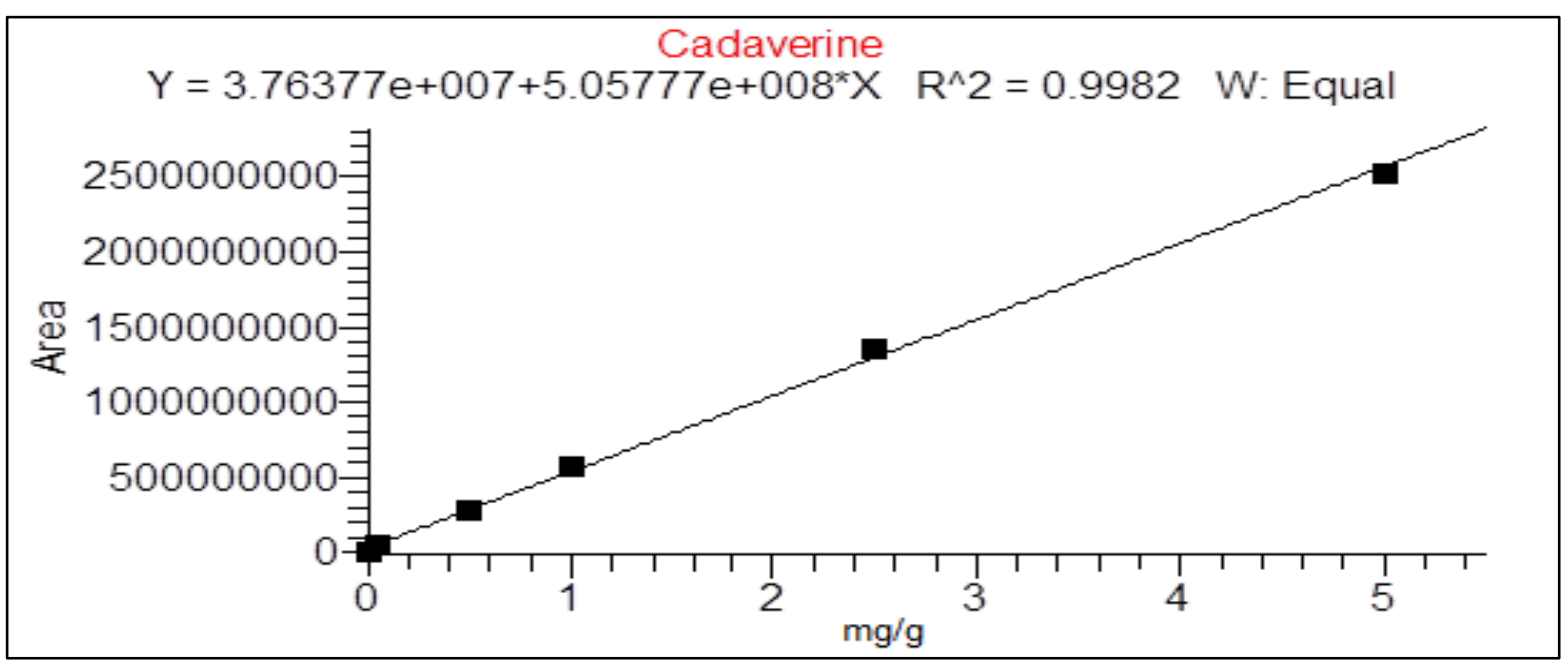

Figure (3): Calibration graph for quantitative analysis of cadaverine by GC-MS.

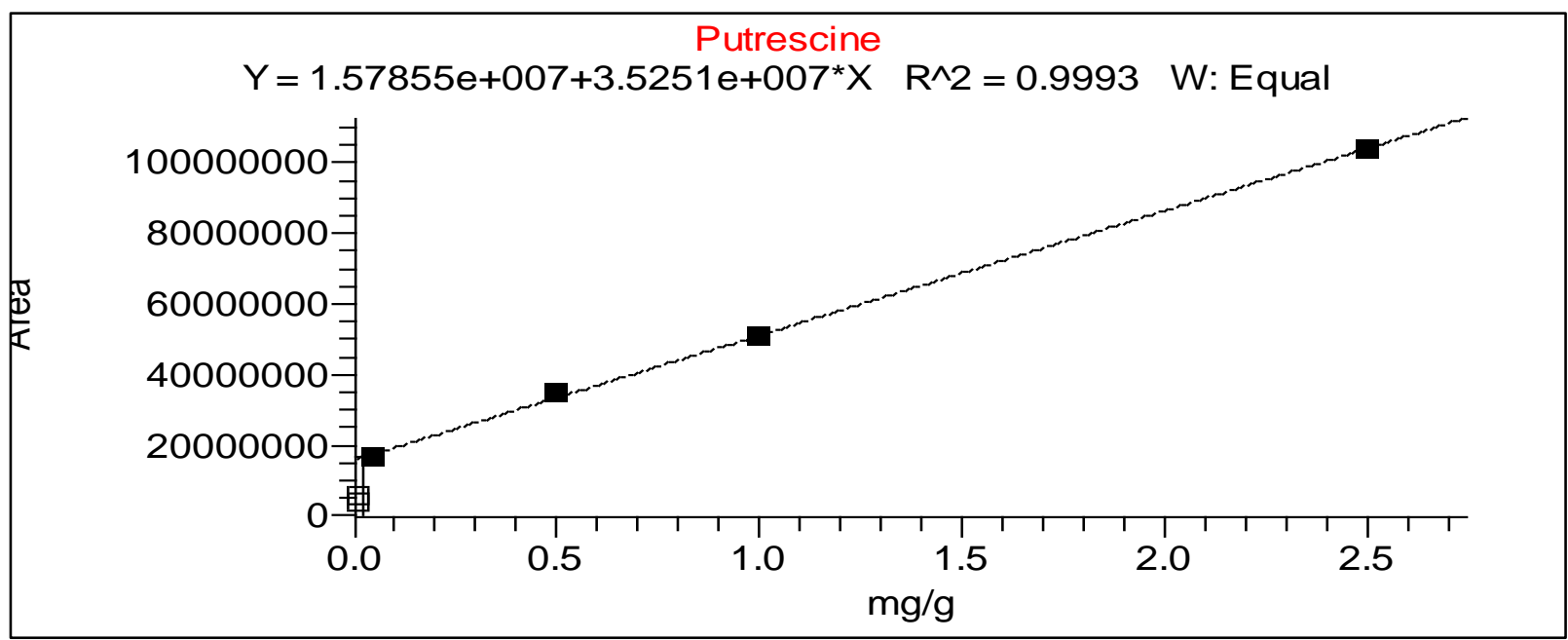

Figure (4): Calibration graph for quantitative analysis of putrescine by GC-MS

The present work showed that both Cad and Put were increased in the brain tissue samples if the PMI was increased (Table 2). There was a statistically highly significant $(\mathrm{p}<0.0001)$ correlation between both Cad and Put levels and the progressive timing of brain aliquot analysis, with a correlation coefficient equal to 0.890 and 0.998 , respectively (Table 3 ).

Table (2): Timing of brain aliquots analysis (representing progressive postmortem interval) and increasing concentration of cadaverine and putrescine for the three studied cases:

\begin{tabular}{|l|c|c|c|c|c|c|}
\hline \multirow{2}{*}{$\begin{array}{c}\text { Timing } \\
(\text { PMI) }\end{array}$} & \multicolumn{3}{|c|}{ Cadaverine (mg/g) } & \multicolumn{3}{c|}{ Putrescine (mg/g) } \\
\cline { 2 - 7 } & Case 1 & Case 2 & Case 3 & Case 1 & Case 2 & Case 3 \\
\hline PMI 1 (12 h) & 0.032 & 0.042 & 0.039 & 0.114 & 0.117 & 0.116 \\
\hline PMI 2 (24 h) & 0.040 & 0.055 & 0.053 & 0.154 & 0.158 & 0.155 \\
\hline PMI 3 (36 h) & 0.047 & 0.058 & 0.063 & 0.184 & 0.188 & 0.185 \\
\hline PMI 4 (48 h) & 0.052 & 0.061 & 0.073 & 0.214 & 0.219 & 0.223 \\
\hline PMI 5 (60 h) & 0.066 & 0.072 & 0.081 & 0.247 & 0.252 & 0.254 \\
\hline
\end{tabular}

PMI: postmortem interval, Case 1: chest stab wound, Case 2: chest stab wound, Case 3: abdominal stab wound. 
Table (3): Statistical correlation between progressive timing of brain aliquot analysis (representing postmortem interval) and levels of cadaverine and putrescine:

\begin{tabular}{|l|l|l|}
\hline Compound & \multicolumn{1}{|c|}{ r } & \multicolumn{1}{c|}{ P value } \\
\hline Cadaverine (mg/g) & 0.890 & $<0.001^{*}$ \\
\hline Putrescine (mg/g) & 0.998 & $<0.001^{*}$ \\
\hline \multicolumn{3}{|c|}{$* \mathbf{p}<\mathbf{0 . 0 0 1}=$ highly significant }
\end{tabular}

There was a statistically insignificant difference between the means of the repeated measures of $\mathrm{Cad}$ and Put in the three studied brains at the $5 \%$ significance level (F-ratio 1.48 and 0.01; $\mathrm{p}=0.266$, and 0.99 respectively) (Table 4).

Table (4): Mean, standard deviation, minimum and maximum values obtained for cadaverine and putrescine levels in different studied cases:

\begin{tabular}{|c|c|c|c|c|c|c|c|c|}
\hline \multirow{2}{*}{ Cases } & \multicolumn{3}{|c|}{ Cadaverine (mg/g) } & \multicolumn{5}{c|}{ Putrescine (mg/g) } \\
\cline { 2 - 10 } & Mean & Stand. Dev. & Min. & Max. & Mean & Stand. Dev. & Min. & Max. \\
\hline Case 1 & 0.047 & 0.013 & 0.03 & 0.07 & 0.183 & 0.052 & 0.114 & 0.247 \\
\hline Case 2 & 0.058 & 0.01 & 0.04 & 0.07 & 0.187 & 0.052 & 0.117 & 0.252 \\
\hline Case 3 & 0.062 & 0.017 & 0.04 & 0.08 & 0.187 & 0.054 & 0.116 & 0.254 \\
\hline F test & \multicolumn{3}{|c|}{1.48} & \multicolumn{5}{c|}{0.01} \\
\hline P value & \multicolumn{3}{|c|}{0.266} & & \multicolumn{7}{c|}{} \\
\hline
\end{tabular}

$$
\mathbf{p}>\mathbf{0 . 0 5}=\text { non-significant }
$$

The present study designed equations for estimating the PMI based on the determined Cad and Put levels in brain tissues; in case of Cad [Cad level " $y$ " = $(0.03+8.33 \mathrm{E}-3 *$ timing " $\mathrm{x}$ ")], this equation interprets $75.2 \%$ of the variability $\left(\mathrm{R}^{2}\right)$ in the levels of Cad after transforming to a reciprocal scale to linearize the model, i.e. $75.2 \%$ of the variability in Cad level is due to the progressive timing of sampling (progressive PMI). Whereas in the case of Put [Put level " $y "=(0.09+0.03 *$ timing " $x$ ")], this equation interprets $99.5 \%$ of the variability $\left(\mathrm{R}^{2}\right)$ in the levels of Put after transforming to a reciprocal scale to linearize the model, i.e., $99.5 \%$ of the variability in Put level is due to the progressive timing of sampling (progressive PMI), (Fig. 5 \& 6).

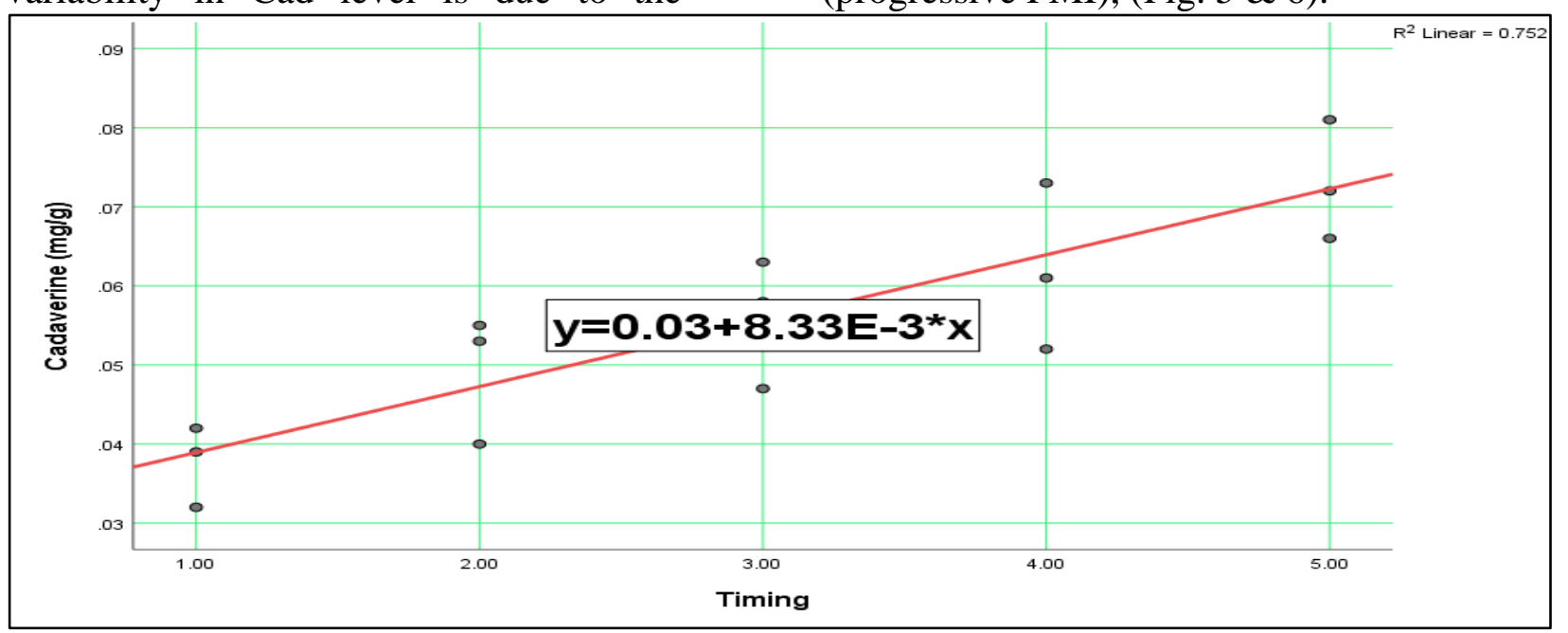

Figure (5): Squared (X) model describing the relationship between cadaverine levels and the progressive timing of sampling (progressive postmortem interval). The red line corresponds to the exponential equation. 


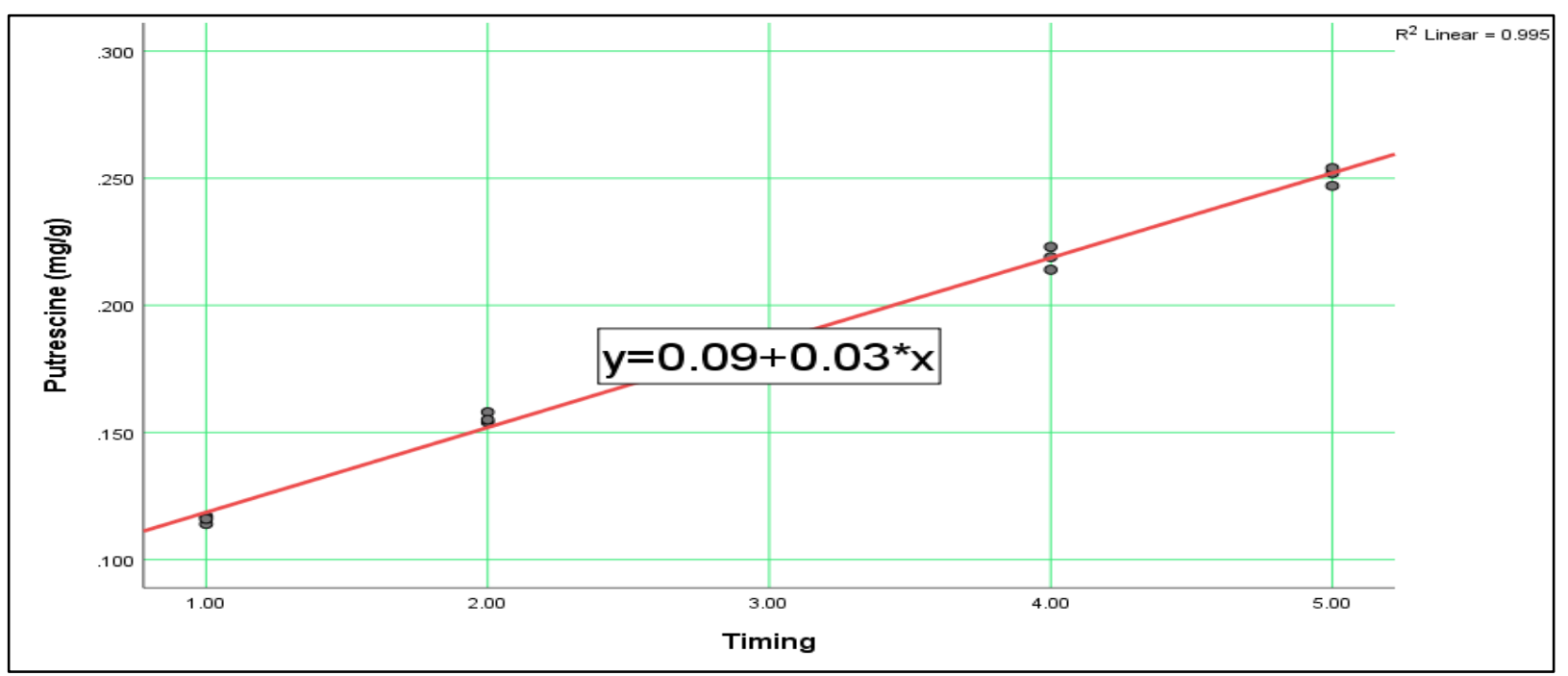

Figure (6): Squared (X) model describing the relationship between putrescine levels and the progressive timing of sampling (progressive postmortem interval). The red line corresponds to the exponential equation.

\section{DISCUSSION}

Authentic postmortem interval (PMI) estimation is a crucial, challenging, and a duty in forensic pathology, it is considered an essential step in criminal investigations (Ceciliason et al., 2018; Gelderman et al., 2019). Developing new PMI estimation methods is pointedly needed as traditional methods are highly affected by several influences (Ehrenfellner et al., 2017).

Advances in the analytical methods used for isolation of the accumulating decomposition by-products, especially that of proteins degradation, such as cadaverine (Cad) and putrescine (Put), can provide new, reliable, and valuable biomarkers for PMI estimation (Choi et al., 2019; Nolan et al., 2019b). Balta et al. (2020) stated that $\mathrm{Cad}$ and Put are considered important tissue decomposition indicators in human cadavers, food stuffs, and even living human oral cavity (oral malodor).

In the current work, the GC-MS technique was used to measure the concentration of both Cad and Put in human brain tissue samples to determine the PMI. Pelletti et al. (2019) validated a method using the GC-MS technique to measure the levels of Cad and Put in PM human brain tissue samples. Dai et al. (2019) stated that GC-MS is deemed an ideal analytical method for PMI determination, because of its accessible standard database, besides its premium separating and qualitative powers.

Also, Li et al. (2017) concluded that GC-MS is a valuable technique used for PMI estimation by identifying of several endogenous molecules present in different body tissues, with high recognition capability. Balta et al. (2020) measured the levels of $\mathrm{Cad}$ and Put in postmortem human liver tissue samples using the GC-MS technique. Earlier, Chen et al. (2010) successfully used high-resolution capillary GC-MS to measure the increased polyamines levels (Put and spermidine) in PM human brain tissue samples. An important point to be considered is that $\mathrm{Cad}$ and Put are members of the biogenic polyamine family, with comparatively high concentrations in the brain's tissue, where they have essential functions (Paterson et al., 2019).

Ioan et al. (2017) illustrated that as the PM decay of proteins proceeded, biogenic amines as by-products accumulated, e.g., putrescine (L-ornithine decarboxylation), and cadaverine (L-lysine decarboxylation). These volatile compounds are responsible for the characteristic smell of putrefaction. Izquierdo et al. (2018); Ismail and Chong, (2019) stated that Cad and Put are present in tissues of all animal kingdom (from bacteria to mammals). The 
production of these volatile diamines is increased after death as a result of organic tissues decomposition, producing the characterized dead smell.

Li et al. (2020) stated that cellular autolysis and microbial activity presented in the cadaver could catalyze lysine and ornithine into odorous molecules such as Cad and Put, respectively. Feddern et al. (2019) stated that the essential requirements for significant biogenic amines ( $\mathrm{Cad}$ and Put) synthesis are: the abundance of free amino acids, the existence of decarboxylase-positive microorganisms, plus the circumstances that favor bacterial growth (decomposition).

This work presented a simple, easy, and more practical brain tissue sampling for PMI estimation (using only small samples " $5 \mathrm{gm}$ " of cerebral cortex). The authors also used short time intervals ( $12 \mathrm{~h}$ interval), which have a more beneficial impact on PMI estimation. The present work showed that both Cad and Put levels increased in the brain tissue samples as long as the PMI increased and that there was a statistically highly significant ( $p<0.0001)$ linear correlation between both Cad and Put levels and the timing of brain aliquot analysis (postmortem interval). Also, the present study designed equations for estimating the PMI based on the determined Cad and Put levels in brain tissues [Cad level $=(0.03+$ 8.33 E- $3 *$ timing $)$; Put level $=(0.09+$ $0.03 *$ timing]. Moreover, the current work found that Put as a biomarker of PMI was more accurate than $\mathrm{Cad}$, as $99.5 \%$ of the variability of Put level was due to the progressive timing of sampling (progressive PMI), while in the case of cadaverine, $75.2 \%$ of the variability of Cad level was due to the progressive timing of sampling (progressive PMI).

This was in line with Pelletti et al. (2019), who studied the levels of polyamines (Cad and Put) in PM human brain tissue samples using GC-MS and concluded that they were significantly increased with time as the PMI increased and that there was a significant correlation between both Cad and Put and the PMI. Donaldson and Lamont (2015) stated that decomposition end-products such as Cad and Put, measured by GC-MS technique, in samples from various human body organs, e.g., brain, heart, and muscles, resulted in patterns valuable for estimation of PMI. Earlier Vass et al. (2002) also, measured the levels of both Cad and Put in the human brain and other organ tissue sample, and correlated their levels with the PMI revealing that both Cad and Put were useful biomarkers for PMI estimation.

On the other hand, Dekeirsschieter et al. (2009); Agapiou et al. (2015) found that the biogenic amines, Cad and Put were not detected in decomposed pigs' carcasses using GC-MS. They passively collected the biogenic amines released from decaying pig by special adsorbent tubes. This may be explained by the fact that both Cad and Put, are highly volatile polar substances (Hoffman et al., 2005; Balta et al., 2020), and to be successfully detected in tissue samples, special precautions, and preparation steps (isolation and derivatization) should be done to detect these volatile compounds, as was performed in this work.

\section{CONCLUSION}

- Both Cad and Put are considered valuable biomarkers for estimating the PMI from the decomposing brain tissues, as:

1. Both Cad and Put levels increased in the brain tissue samples as long as the PMI increased.

2. There was a statistically highly significant $(p<0.0001)$ linear correlation between Cad and Put levels and the PMI.

- The present study designed equations for estimating the PMI based on the determined PM Cad and Put levels in brain tissues.

- Put as a biomarker of PMI was more accurate than Cad.

\section{LIMITATIONS}

- Small-sized sample (due to financial and administrative issues). 


\section{RECOMMENDATIONS} needed.

- Studies on large-scale samples are

- Studies on different body organs other than the brain are advised.

\section{ACKNOWLEDGMENT}

Deep appreciation to our colleges at the Faculty of Medicine, Benha University, for their continuous support, http://www.fmed.bu.edu.eg. Many thanks to our college at Qalubia Forensic Medicine Department, Forensic Medicine Authority, Ministry of Justice for their cooperation in samples collection. Many thanks to Dr. Mamoun S.M. Abd El-Kareem (Associate Professor at the Egyptian Atomic Energy Authority, Nuclear Research Center, Experimental physics depart, GC-MS Laboratory), and Dr. Mohamed R. Elnagar, (Department of Pharmacology and Toxicology, Faculty of Pharmacy, AlAzhar University, Cairo, Egypt), for their valuable help in the technical part of this work.

\section{REFERENCES}

Agapiou, A.; Zorba, E.; Mikedi, K.; McGregor, L.; Spiliopoulou, C.; Statheropoulos, M.; et al. (2015): Analysis of volatile organic compounds released from the decay of surrogate human models simulating victims of collapsed buildings by thermal desorption-comprehensive twodimensional gas chromatography-time of flight mass spectrometry. Analyt. Chimica Acta, 883: 99-108. doi: 10.1016/j.aca.2015.04.024

Andersson, M.G.; Ceciliason, A.; Sandler. H. and Mostad, P. (2019): Application of the Bayesian framework for forensic interpretation to casework involving postmortem interval estimates of decomposed human remains. Foren. Sci. Inter., 301: 402414.

doi:

10.1016/j.forsciint.2019.05.050

Balta, J.Y.; Blom, G.; Davidson, A.; Perrault, K.; Cryan, J.F.;
O'Mahony, S.M.; et al. (2020):

Developing a quantitative method to assess the decomposition of embalmed human cadavers. Foren. Chem., 18: 100235. doi: 10.1016/j.forc.2020.100235

Ceciliason, A.; Andersson, M.G.; Lindström, A. and Sandler, $\mathbf{H}$. (2018): Quantifying human decomposition in an indoor setting and implications for postmortem interval estimation. Foren. Sci. Int., 283:180189. doi: 10.1016/j.forsciint.2017.12.026

Chen, G.G.; Fiori, L.M.; Moquin, L.; Gratton, A.; Mame r, O.; Mechawar, N.; et al. (2010): Evidence of altered polyamine concentrations in cerebral cortex of suicide completers. Neuropsychopharmacol., 35: 14771484. doi: $10.1038 /$ npp.2010.17.

Choi, K.M.; Zissler, A.; Kim, E.; Ehrenfellner, B.; Cho, E.; Lee, S.; et al. (2019): Postmortem proteomics to discover biomarkers for forensic PMI estimation. Inter. J. Leg. Med., 133 (3): 899-908. doi: 10.1007/s00414-01902011-6

Connor, M.; Baigent, C. and Hansen, F. S. (2019): Measuring Desiccation Using Qualitative Changes: A Step Toward Determining Regional Decomposition Sequences. J. Foren. Sci., 64 (4): 1004-1011. doi: 10.1111/1556-4029.14003

Dai, X.; Fan, F.; Ye, Y.; Lu, X.; Chen, F.; Wu, Z.; et al. (2019): An experimental study on investigating the postmortem interval in dichlorvos poisoned rats by GC/MS-based metabolomics. Leg. Med., 36: 28-36. doi: 10.1016/j.legalmed.2018.10.002

Dekeirsschieter, J.; Verheggen, F.J.; Gohy, M.; Hubrecht, F.; Bourguignon, L. Lognay, G.; et al. (2009): Cadaveric volatile organic compounds released by decaying pig carcasses (Sus domesticus L.) in different biotopes. Foren. Sci. Inter., 
189: $\quad 46-53 . \quad$ doi:

10.1016/j.forsciint.2009.03.034

Donaldson, A.E. and Lamont, I.L. (2015): Metabolomics of postmortem blood: identifying potential markers of postmortem interval. Metabolomics, 11: 237-245. doi: 10.1007/s11306-0140691-5

Ehrenfellner, $\quad$ B.; $\quad$ Zissler, A.; Steinbacher, P.; Monticelli, F.C. and Pittner, S. (2017): Are animal models predictive for human postmortem muscle protein degradation? Inter. J. Leg. Med., 131(6), 1615-1621. doi:10.1007/s00414-017-1643-1.

Feddern, V.; Mazzuco, H.; Fonseca, F.N. and De Lima, G.J.M.M. (2019): A review on biogenic amines in food and feed: toxicological aspects, impact on health and control measures. Anim. Prod. Sci., 59: 608-618. doi:10.1071/AN18076

Gelderman, H.T.; Kruiver, C.A.; Oostra, R.J.; Zeegers, M.P. and Duijst, W.L.J.M. (2019): Estimation of the postmortem interval based on the human decomposition process. J. Foren. Leg. Med., 61: 122-127. doi:10.1016/j.jflm.2018.12.004

Hess, C.; Sydow, K.; Kueting, T.; Kraemer, M. and Maas, A. (2018): Considerations regarding the validation of chromatographic mass spectrometric methods for the quantification of endogenous substances in forensics. Foren. Sci. Inter., 283: 150-155. doi: 10.1016/j.forsciint.2017.12.019

Hoffman, E.M.; Curran, A.M.; Dulgerian, N.; Stockham, R.A. and Eckenrode, B.A. (2005): Characterization of the volatile organic compounds present in the headspace of decomposing human remains. Foren. Sci. Inter., 186: 6-13. doi: 10.1016/j.forsciint.2008.12.022

Ioan, B.G.; Manea, C.; Hanganu, B.; Statescu, L.; Solovastru, L.G. and Manoilescu, I. (2017): The chemistry decomposition in human corpses. Revista De Chimie, 68 (6): 1352-1356.
Ismail, S.S. and Chong, Z.Y. (2019): Decomposition of abdomen fatty flesh of cadaver buried in nami series soil of bukit kor Terengganu. Materials Today: Proceedings, 19: 1426-1433.

Izquierdo, C.; Gómez-Tamayo, J.C.; Nebel, J.C.; Pardo, L. and Gonzalez, A. (2018): Identifying human diamine sensors for death related putrescine and cadaverine molecules. PLoS Comput. Biol., 14 (1): e1005945. doi: 10.1371/journal.pcbi.1005945

Kaliszan, M. and Wujtewicz, M. (2019): Eye temperature measured after death in human bodies as an alternative method of time of death estimation in the early postmortem period. A successive study on new series of cases with exactly known time of death. Leg. Med., 38: 10-13. doi:10.1016/j.legalmed.2019.03.0 04

Khothari, C.R. (2004): Research Methodology: Methods and Techniques, New Age International, New Delhi.

Li, C.; Ma, D.; Deng, K.; Chen, Y.; Huang, P. and Wang, Z. (2017): Application of MALDI-TOF MS for estimating the postmortem interval in rat muscle samples. J. Foren. Sci., 62 (5): 1345-1350. doi: 10.1111/15564029.13413

Li, H.; Yang, E.; Zhang, S.; Zhang, J.; Yuan, L.; Liu, R.; et al. (2020): Molecular characterization of gut microbial shift in SD rats after death for 30 days. Archives Microbiol., 202: 1763-1773. doi: 10.1007/s00203-02001889-w

Marhoff-Beard, S.J.; Forbes, S.L. and Green, H. (2018): The validation of 'universal' PMI methods for the estimation of time since death in temperate Australian climates. Foren. Sci. Inter., 291: 158-166. doi: 10.1016/j.forsciint.2018.08.022

Musile, G.; Gottardo, R.; Palacio, C.; Shestakova, K.; Raniero, D.; De Palo, E.F.; et al. (2019): Development 
of a low-cost gas diffusion device for ammonia detection in the vitreous humor and its preliminary application for estimation of the time since death. Foren. Sci. Inter., 295: 150-156. doi: 10.1016/j.forsciint.2018.12.012

Navarro, J.; Sanz-Vicente, I.; Lozano, R.; Marcos, S. and Galban, J. (2020): Analytical possibilities of Putrescine and Cadaverine enzymatic colorimetric determination in tuna based on diamine oxidase: A critical study of the use of ABTS. Talanta, 208: 120392. doi: 10.1016/j.talanta.2019.120392

Nolan, A.N.; Mead, R.J.; Maker, G. and Speers, S.J. (2019b): A review of the biochemical products produced during mammalian decomposition with the purpose of determining the postmortem interval. Austr. J. Foren. Sci., $52 \quad$ (4): 477-488. doi:10.1080/00450618.2019.15895

Nolan. A.N.; Mead, R. J.; Maker, G.; Bringans, S.; Chapman, B. and Speers, S.J. (2019a): Examination of the temporal variation of peptide content in decomposition fluid under controlled conditions using pigs as human substitutes. Foren. Sci. Inter., 298: $161-168 . \quad$ doi: 10.1016/j.forsciint.2019.02.048

Paterson, B.M.; Cullinane, C.; Crouch, P.J.; White, A.R.; Barnham, K.J.; Roselt, P.D.; et al. (2019): Modification of biodistribution and brain uptake of copper Bis (thiosemicarbazonato) complexes by the incorporation of amine and polyamine functional groups. Inorg. Chem., 58: 4540-4552. doi: 10.1021/acs.inorgchem.9b00117

Pelletti. G.; Garagnani, M.; Barone, R.; Boscolo-Berto, R.; Rossi, F.; Morotti,
A.; et al. (2019): Validation and preliminary application of a GC-MS method for the determination of putrescine and cadaverine in the human brain: a promising technique for PMI estimation. Foren. Sci. Inter., 297: 221-227. doi: 10.1016/j.forsciint.2019.01.025

Qi, X.; Wang, W.; Wang, J.; Yang, J. and Shi, Y. ((2018): Highly selective colorimetric detection of putrescine in fish products using ophthalaldehyde derivatization reaction. Food Chem., 259: 245-250. doi: 10.1016/j.foodchem.2018.03.131

Shaaban, A.A.; Farrag, I.M. and Bayoumy, E.S. (2017): Estimation of early postmortem interval by biochemical changes in brain and liver of rats using some oxidant and antioxidant parameters. Egyp. J. Foren. Sci. Appli. Toxicol., 17 (1): 147-162. doi: 10.21608/EJFSAT.2017.46108

Vass, A.A.; Barshick, S.A.; Sega, G.; Caton, J.; Skeen, J.T.; Love, J.C.; et al. (2002): Decomposition chemistry of human remains: A new methodology for determining the postmortem interval. J. Foren. Sci., 47 (3): 542-553.

Wu, Z.; Lu, X.; Chen, F.; Dai, X.; Ye, Y.; Yan, Y.; et al. (2018): Estimation of early postmortem interval in rats by GC-MS-based metabolomics. Leg. Med., 31:42-48. doi: 10.1016/j.legalmed.2017.12.014

Ying, X.; Yoshioka, H.; Liu, C. and Sassa, F. (2018): Molecular imprinting technique in putrescine visualized detection. Sensors and Actuators B., 258: 870-880. doi: 10.1016/j.snb.2017.11.128 


\section{مستويات الكادافيرين والبيوترسين في نسيج المخ البشري لتقلير فترة ما بعد الوفاة}

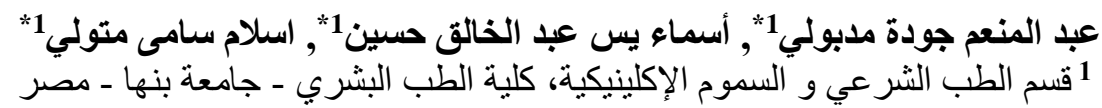

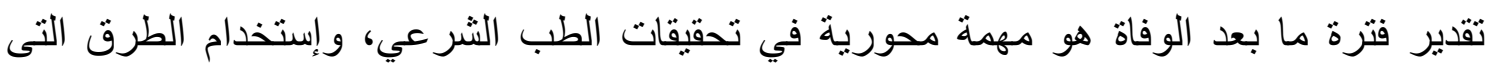

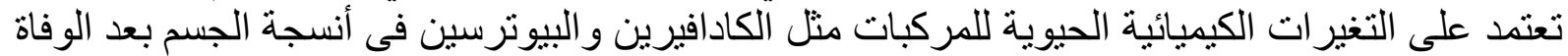

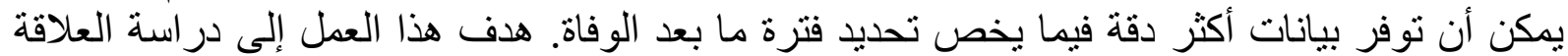

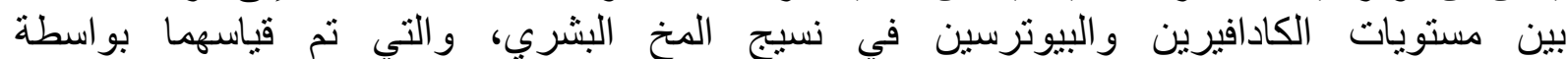

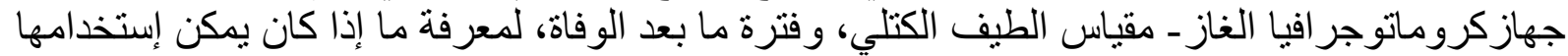

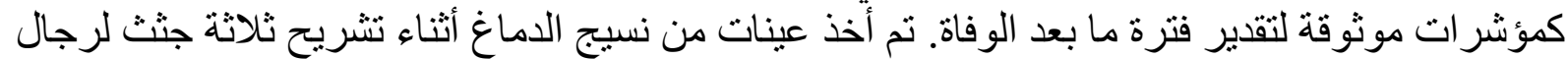

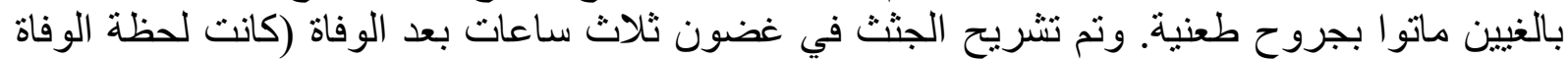

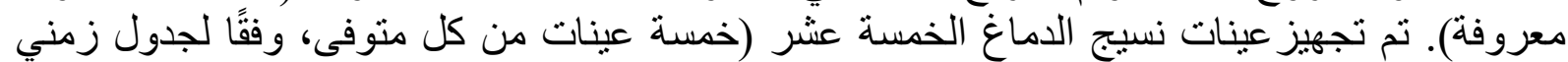

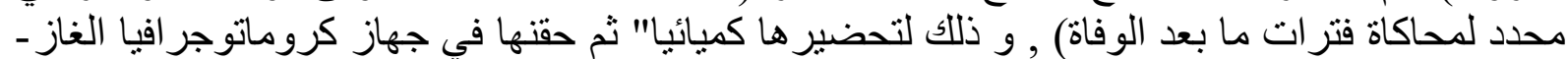

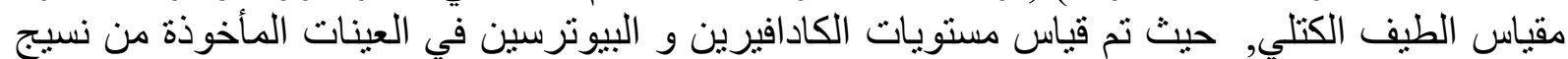

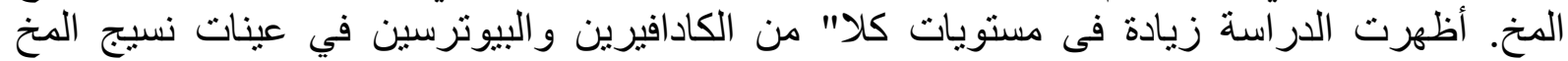

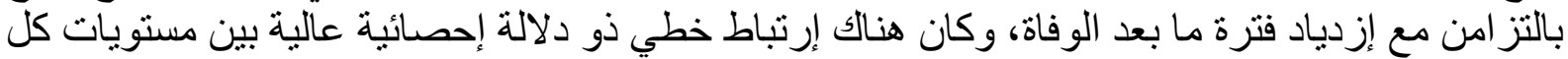

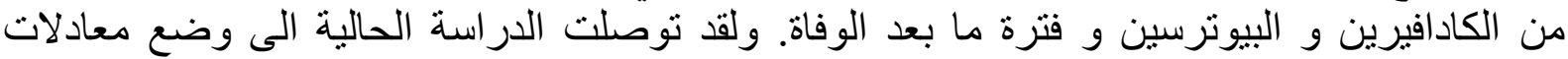

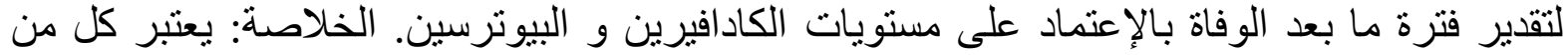

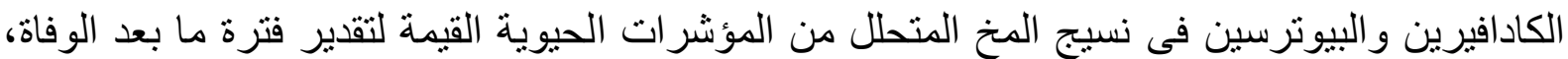
مع الأحذ فى الإعتبار ان البيونرسين كان أكثر دقة فى تحديد فترة ما بعد الوفاة من الكادافيرين. 